\title{
História em quadrinhos: Uma mediadora no processo de ensino- aprendizagem em Densidade dos Gases do Ensino de Química
}

\section{Comics: A mediator in the teaching-learning process in Chemistry Teaching Gas Density}

\author{
Antony Ernesto dos Santos Silva ${ }^{1 *}$ \\ 'Licenciado em Química, Especialista em Ensino de Ciências Naturais, Mestrando em Ciências Farmacêuticas pela Universidade Federal do \\ Alagoas. Brasil. E-mail: antonyessilva@gmail.com * Autor para correspondência
}

\author{
Palavras-chave \\ História em Quadrinhos \\ Ensino-aprendizagem \\ Densidade dos Gases \\ Ensino de Química
}

\begin{abstract}
Este trabalho teve por objetivo aplicar uma História em Quadrinhos para atuar como mediadora no processo de ensino-aprendizagem em Densidade dos Gases do Ensino de Química, numa turma do segundo ano do ensino médio de uma instituição federal do estado de Alagoas, com total de 23 alunos presentes. Para colher os dados, utilizou-se um questionário sobre o assunto em tese, que foi aplicado antes e depois da leitura da História em Quadrinhos. Os resultados mostraram que houve um aumento de 47,8\% no número de alunos que acertaram todo o questionário, além da diminuição do número de alunos que erraram determinadas questões do respectivo questionário. Este fato mostra que a História em Quadrinhos, mencionada neste trabalho, pode ser utilizada como mediadora no processo de ensino-aprendizagem em Densidade dos Gases do Ensino de Química.
\end{abstract}

\section{INTRODUÇÃO}

Há muito, se tem estudado formas de prender a atenção dos alunos às aulas ensinadas, independente da disciplina. Quando se trata das disciplinas de exatas, particularmente a de Química, este desafio se torna maior, uma vez que os discentes não têm afinidade com a mesma e a julga difícil de estudar. Este problema pode ser contornado se o professor utilizar uma ferramenta que auxilie na compreensão dos alunos e que contextualize os conteúdos que estão sendo passados.

As Histórias em Quadrinhos (HQs) têm por objetivo deixar os alunos mais próximos dos conteúdos ensinados, o que fará com que eles tenham um aprendizado mais eficiente, já que elas atuam como mediadoras no processo de ensinoaprendizagem, além de contextualizar os conteúdos passados.

Assim, o objetivo deste trabalho foi utilizar uma $\mathrm{HQ}$ na perspectiva dela atuar como mediadora entre o ensino e aprendizagem do tópico Estudos dos Gases, no assunto Densidade dos Gases, em uma turma do segundo ano do ensino médio de uma instituição federal do estado de Alagoas. A aplicação da $\mathrm{HQ}$ para o assunto em tese deve-se ao fato de que ele é passado de forma abstrata, o que pode afetar para pior o aprendizado dos alunos, uma vez que não é possível elaborar aulas práticas com gases por serem, em sua maioria, tóxicos e de difícil obtenção.

\section{Breve contexto histórico das HQs}

As HQs já existem, de forma indireta, desde a pré-história. Neste período, os homens procuravam representar nas paredes das cavernas cenas do seu cotidiano, como, por exemplo, os incidentes de suas caçadas. Bem mais adiante, os povos egípcios produziam imagens pintadas ou modeladas no interior dos templos, nos túmulos, nos quais apareciam figuras do faraó, da corte, reportando episódios repletos de símbolos e que representavam cenas de caçadas, de colheitas, de oferendas, ou mesmo cenas domésticas (MOYA, 1996).

De acordo com Palhares (2008), elas surgiram em 1889, na França e em 1896, nos Estados Unidos da América. Já no Brasil, a primeira manifestação de "histórias de características 
quadrinizantes" veio com o cartunista italiano Angelo Agostini, onde seus desenhos eram de teor cômico com cunho crítico. Com base nos trabalhos de Agostini, foi criada em 30 de janeiro de 1869 a primeira HQ brasileira, que foi "As aventuras de Nhô Quin". Publicada pela revista Vida Fluminense, do Rio de Janeiro, a história contava, em episódios, as desventuras de um homem simples do interior do Brasil.

Desde então várias HQs foram criadas. Cada uma delas com abordagens diferentes de histórias, como ficção científica, terror, ação e aventuras. Atualmente os mais famosos produtores de HQs no Brasil são Maurício de Sousa com a Turma da Mônica e Ziraldo com a Turma do Pererê e o Menino Maluquinho (PALHARES, 2008).

\section{Ensino de Química e HQs}

Segundo Palhares (2008), as HQs trazem uma nova forma de narrativa que tem como ponto principal a união de duas linguagens, a verbal com a não-verbal, o que lhe confere um grande potencial criativo e comunicativo. De acordo com a autora, a mensagem linguística das HQs compreende um aspecto narrativo, no qual é feita a descrição do quadro, da situação ou das ações e a forma de diálogo. Para Barbosa (2004), as HQs podem vir a ser uma poderosa ferramenta pedagógica. Pois abordam um potencial reflexivo, artístico e pedagógico (PALHARES, 2008).

Visto isto, as HQs foram utilizadas como ferramenta pedagógica no Ensino de História (PALHARES, 2008), como recurso metodológico para o Ensino de Artes (ARAÚJO; NARDIN; TINOCO, 2010), como recurso didático para o Ensino do Corpo Humano em Ciências Naturais (KAWAMOTO; CAMPOS, 2014) e para explicação da História dos Modelos Atômicos no Ensino de Química (AQUINO et. al., 2015). Desta forma percebe-se o uso das $\mathrm{HQ}$ s como um recurso e uma alternativa metodológica, didática e pedagógica a ser utilizada pelo professor para garantir uma aprendizagem significativa a seus alunos.

No Ensino de Química, as HQs podem ser utilizadas como mediadoras no processo de ensino-aprendizagem dos alunos, uma vez que assuntos da química são muitos deles, abstratos e de difícil compreensão, tornado assim a disciplina de química chata e desmotivante (SANTOS; SILVA; ACIOLI, 2012 e KUNDLATSCH; MARQUES; SILVA, 2015). Para Zanon e Palharini (1995) um dos motivos de a química ser considerada chata, é a não contextualização dos conteúdos ensinados em sala de aula. Quando isto acontece estes se tornam distantes, assépticos e difíceis, não despertando o interesse e a motivação dos alunos, o que, por consequência, faz com que a aprendizagem do Ensino da Química seja dificultada.

Sendo assim, as HQs podem ser utilizadas para contextualizar um determinado assunto de Química que seja de difícil compreensão. Mas o uso das HQs não deve ser feito de qualquer forma. Conforme Uchôa, Júnior e Fancisco (2012), para um bom uso das HQs é de extrema importância o papel do educador, como orientador, para promoção de debates dos temas abordados em cada história. Desta forma o professor de Química pode abrir uma discussão antes, durante ou depois da leitura da $\mathrm{HQ}$, garantindo aos alunos um pensamento crítico, e, consequentemente, a consolidação da aprendizagem do assunto abordado.

Ao estudarmos os gases, na disciplina de Química, percebemos o quão abstrato é o assunto, já que dificilmente o professor pode fazer qualquer atividade prática utilizando gases, uma vez que eles são, em sua maioria, tóxicos e de difícil obtenção. Assim, o uso das HQs pode contornar este inconveniente, além de auxiliar o processo de ensinoaprendizagem dos alunos sobre este assunto da disciplina de Química.

\section{MATERIAL E MÉTODOS}

Para a realização deste trabalho, foram utilizados, como materiais de pesquisa, uma $\mathrm{HQ}$ (Figura 5), produzida pelo autor utilizando o Pixton $\complement$, sobre o assunto Densidade dos Gases e um questionário sobre o tópico citado (Questionário aplicado, p.87), para colher os dados.

Este trabalho foi realizado em uma turma de ensino médio, na disciplina de Química de uma instituição federal do estado de Alagoas, no total de 23 alunos presentes, aproximadamente três meses após as aulas sobre Densidade dos Gases serem dadas. Primeiramente foi distribuído para a turma um questionário sobre o assunto Densidade dos Gases, para colher os dados dos desempenhos iniciais dos alunos. Em seguida, foi aberta uma discussão (15 minutos) envolvendo teoria e cálculos sobre o tópico citado, para aguçar o conhecimento dos alunos.

Posteriormente, a $\mathrm{HQ}$ foi distribuída para toda a turma. Esperou-se cerca de 20 minutos para que todos a lessem. Logo após, o mesmo questionário, aplicado no início do trabalho, foi re-aplicado, a fim de saber o quanto que a $\mathrm{HQ}$ contribuiu para o aumento dos conhecimentos dos alunos sobre o tópico citado.

Ao fim do trabalho, foi pedido para que os alunos expressassem suas opiniões através de um texto de poucas linhas (< 10 linhas), a fim de saber o que achavam sobre a HQ e a metodologia utilizada.

\section{RESULTADOS E DISCUSSÃO}

A HQ utilizada neste trabalho conta a história de um 
homem que faz uma viagem de balão durante as férias do trabalho, onde nesta viagem ele descobre que o balão flutua por conta da ação da densidade dos gases. Ele percebe isto ao relembrar das suas aulas da disciplina de Química, principalmente sobre as agitações das moléculas gasosas quando são aquecidas, o que fazem com que elas sofram vários tipos de movimentos (translacionais, vibracionais e rotacionais), aumentando o volume do gás no interior do balão, resultando na diminuição da sua densidade, o que faz o balão flutuar. Isto Pode ser observado nas tiras da página 6 da respectiva $\mathrm{HQ}$ (Figura 1 ).

Figura 1. Tiras da página 6 da HQ utilizada.
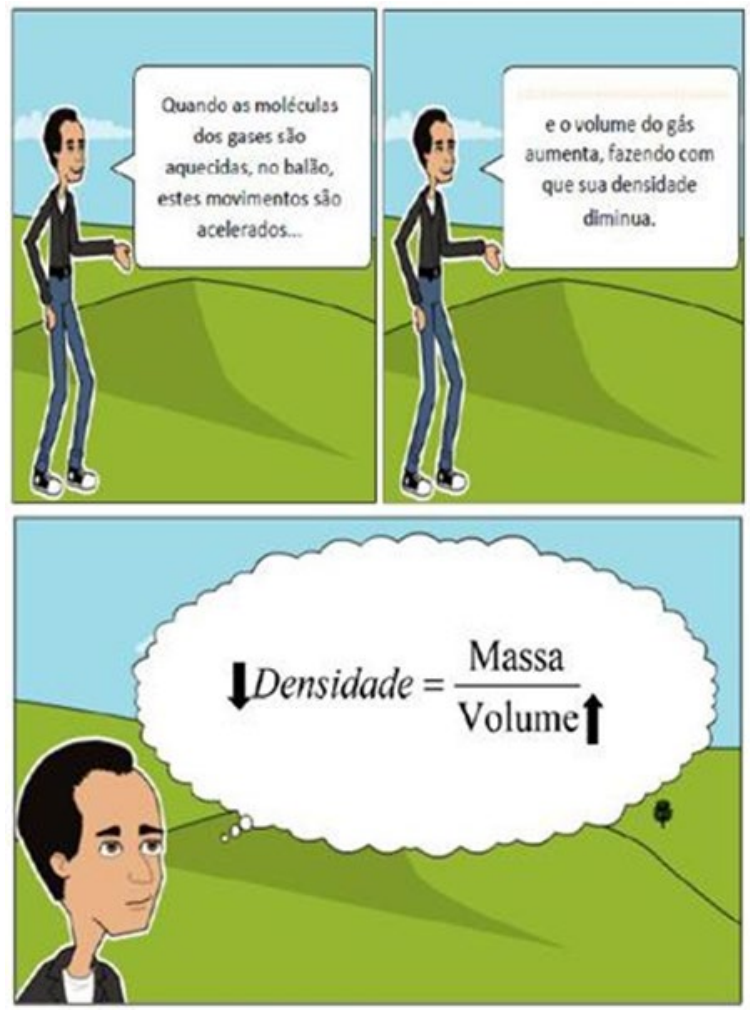

Fonte: Autor (2019).

Este fenômeno também pode ser observado no funcionamento de um aparelho de ar condicionado e na altura em que ele é instalado. Estes aparelhos são preferencialmente instalados em partes altas dos estabelecimentos, já que o ar frio é mais denso que o ar quente, por isso ele tende a descer para a parte inferior do ambiente refrigerando-o. Exemplos em que encontramos a presença da densidade no dia-a-dia foram abordados na discussão feita antes da distribuição da $\mathrm{HQ}$, conforme a metodologia citada acima.

$\mathrm{Na} \mathrm{HQ}$ deste trabalho, foi mencionado o mesmo fenômeno, de forma qualitativa, ao observar a forma que o balão flutua, os gases no interior do balão e suas respectivas posições, o que é uma continuação das tiras das páginas citadas acima (Figura 2).
Assim, o homem da HQ finaliza a história mencionando o quão importante foram os conhecimentos adiquiridos na disciplina de Química, tentando desconstruir nos alunos uma fala que se repete entre eles, quando se referem aos assuntos estudados: "para quê eu vou precisar disso na minha vida?". Mostrando também que tais assuntos estudados, na disciplina de Química, ajudam a pensar de forma crítica e a compreender o mundo ao seu redor com um olhar e pensamento mais aguçado.

Figura 2. Tiras das páginas 7 e 8 da $\mathrm{HQ}$ utilizada, onde $\Delta$ é aquecimento.

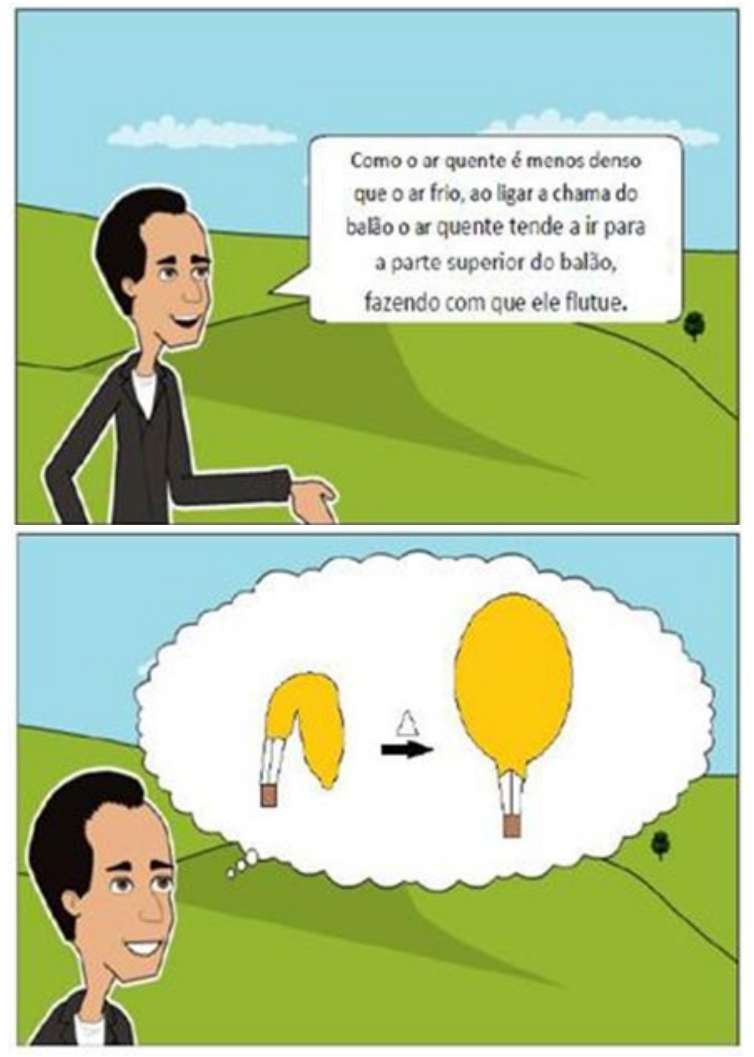

Fonte: Autor (2019)

\section{Resultados e discussões com base no questionário aplicado e nas opiniões dos alunos}

Um questionário foi utilizado para colher os dados dos desempenhos dos alunos, que foi aplicado antes e depois da leitura da $\mathrm{HQ}$ e da discussão que antecedeu a leitura da mesma. Trata-se de um questionário sobre questões básicas deste tópico, a fim de saber se os alunos possuíam os conhecimentos básicos sobre o tópico citado. 0 mesmo foi elaborado com 5 questões, cada questão valendo 2,0 pontos, totalizando 10,0 pontos.

A Figura 3 mostra o desempenho dos alunos antes da aplicação da HQ e da discussão. Percebe-se que a maioria dos alunos tinha um razoável conhecimento básico sobre o tópico apresentado neste trabalho, ao observar que cerca de 9 
alunos conseguiram 3 acertos. Podemos notar também que alguns alunos ( 3 alunos) tinham pouco conhecimento sobre o tópico estudado, acertando apenas 1 questão do questionário. É notório também que tiveram alunos (4 alunos), $17,4 \%$ da turma presente, que conseguiram o número máximo de acertos.

Figura 3. Desempenho dos alunos antes da aplicação da HQ e da discussão.

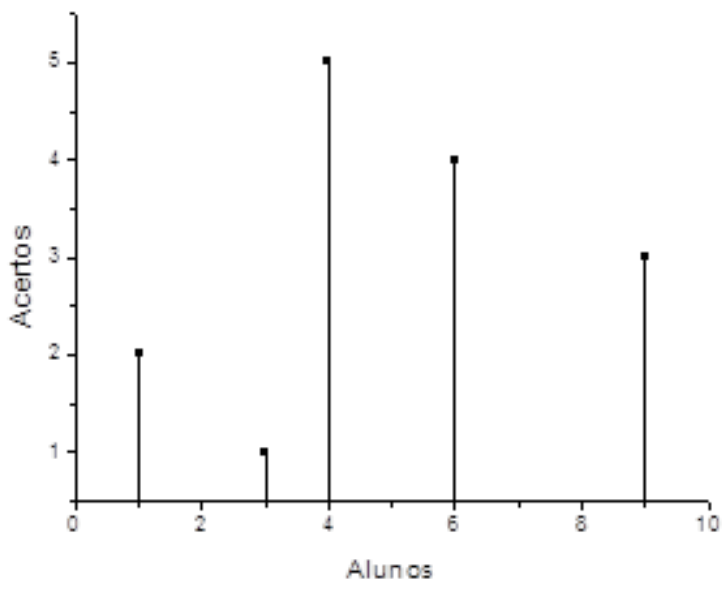

Na Figura 4 estão os dados dos acertos dos alunos obtidos depois da aplicação da HQ e da discussão. Podemos notar que agora o menor número de acertos é de 3 , onde 5 alunos obtiveram este valor. Um número mínimo de 3 alunos obtiveram 4 acertos do questionário. Já desta vez, uma grande maioria de alunos (15 alunos), 65,2\% da turma presente, acertaram todas as 5 questões do questionário utilizado.

Figura 4. Desempenho dos alunos depois da aplicação da História em Quadrinhos e da discussão.

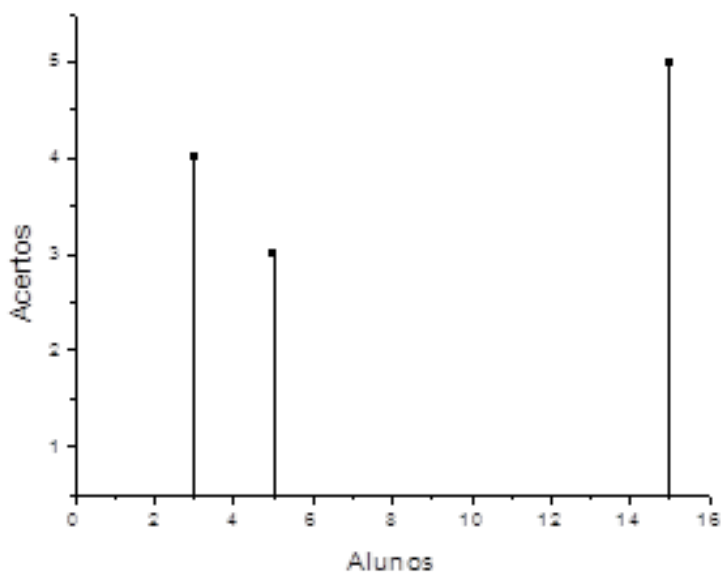

Ao observar os percentuais de acertos antes e depois da aplicação da $\mathrm{HQ}$ e da discussão, percebemos que houve um aumento no número de alunos, $47,8 \%$, que acertaram todas as questões do questionário utilizado neste trabalho.
Verificou-se também, através da opinião dos alunos, que o Ensino de Química, em particular do tópico citado, muitas vezes é abordado de forma muito tradicional, quando os professores e até mesmo os livros não fazem o uso de outras ferramentas de auxílio na aprendizagem, não garantindo a contextualização. Isto é evidenciado, na fala de uma aluna, onde ela diz: "...gostaria que os livros fossem desse jeito. Assim, ficaria mais fácil de entender.". Outro aluno diz: "Achei muito legal e interessante. Foi um meio utilizado onde melhorou muito minha concepção e entendimento sobre o conteúdo...". Tais opiniões e falas mostram que a contextualização, por meio de uma ferramenta metodológica, ajuda na compreensão dos alunos sobre o que está sendo passado para eles.

\section{CONCLUSÕES}

Conclui-se assim que a $\mathrm{HQ}$ apresentada neste trabalho contribui para o melhor aprendizado dos alunos para o assunto Densidade dos Gases, pois além de contextualizar o assunto em tese, ajuda na melhoria do processo de ensinoaprendizagem dos alunos, atuando como mediadora, uma vez que houve um aumento em $47,8 \%$ no número de alunos que acertaram todas as questões do questionário utilizado.

A metodologia utilizada pelo professor, assim como as ferramentas que auxiliam a compreensão do conteúdo passado, pode influenciar na melhoria da aula, tornando-a mais produtiva e atraente, garantido aos alunos, uma forma diferente de aprender, que pode resultar numa aprendizagem mais eficaz dos mesmos.

\section{REFERÊNCIAS}

AQUINO, F. F. et. al. Elaboração, Aplicação e Avaliação de uma HQ Sobre Conteúdo de História dos Modelos Atômicos para o Ensino de Química. Orbital: The Electronic Journal of Chemistry, Mato Grosso do Sul, v.7, n.1, p. 53-58, 2015. Disponível em:<http://dx.doi.org/10.17807/orbital.v7i1.525>. Acesso em: 5 Jun. 2019.

ARAÚJO, G. C.; NARDIN, H. O.; TINOCO, E. F. Criação E Técnica: As Histórias Em Quadrinhos Como Recurso Metodológico Para O Ensino De Arte. Revista Ideia, Santa Catarina, v.1, n.2, 2010. Disponível em: <http://www.esamcuberlandia.com.br/Revistaldea2/arti gos/2010v1n2art03.pdf>. Acesso em: 12 jun. 2019.

BARBOSA, A. Os quadrinhos no ensino de Artes. In: RAMA, A; VERGUEIRO, Waldomiro (Org.). Como usar as histórias em quadrinhos na sala de aula. Contexto, São Paulo, p. 131149, 2004. 
KAWAMOTO, E. M.; CAMPOS, L. M. L. Histórias Em Quadrinhos Como Recurso Didático Para O Ensino Do Corpo HumanoEm Anos Iniciais Do Ensino Fundamental. Ciência \& Educação (Bauru), São Paulo, v.20, n.1, p. 147158, 2014. Disponível em: <http://dx.doi.org/10.1590/1516-731320140010009>. Acesso em: 12 jun. 2019.

KUNDLATSCH, A.; MARQUES, C. A.; SILVA, C. S. Histórias em Quadrinhos no Ensino de Química: análiseda contribuição do desenho e da escrita para o processo deensinoaprendizagem. In:X Encontro Nacional de Pesquisa em Educação em Ciências, área 16, 2015, São Paulo.Anais do X ENPEC. São Paulo: Águas de Lindóia, 2015. Disponível em: <http://www.abrapecnet.org.br/enpec/xenpec/anais2015/lista_area_16.htm>.Acesso em: 20 mai. 2019.

MOYA, A. História da história em quadrinhos. São Paulo: Brasiliense, 1996.

PALHARES, M. C. História em quadrinhos: uma ferramenta pedagógica para o ensino de história. Dia a Dia EducaçãoGoverno do Paraná, Paraná, 2008. Disponível em: <http://www.diaadiaeducacao.pr.gov.br/portals/pde/arq uivos/2262-8.pdf>. Acesso em: 28 mai. 2019.

PIXTON, C. Inc. A melhor maneira de criar quadrinhos. Disponível em: <https://www.pixton.com/br/>. Acesso: 30 abr. 2019.

SANTOS, V. J. R. M.; SILVAF. B.; ACIOLI, M. F. Produção de Histórias em Quadrinhos na abordagem interdisciplinar de Biologia eQuímica. Novas Tecnologias na Educação, Rio Grande do Sul, v.10, n.3, dez. 2012. Disponível em: <https://doi.org/10.22456/1679-1916.36467>. Acesso em: 10 jun. 2019.

UCHÔA, M. A.; JUNIOR, W. E. F.; FRANCISCO, W. Produção e avaliação de uma história em quadrinhos para o ensino de Química. In: XVI Encontro Nacional de Ensino de Química (XVI ENEQ) e X Encontro de Educação Química da Bahia (X EDUQUI), 2012, Bahia. Anais do XVI Encontro Nacional de Ensino de Química/X Encontro de Educação Química da Bahia.Bahia: UFBA, 2012. Disponível em: <https://portalseer.ufba.br/index.php/anaiseneq2012>. Acesso em: 30 mai. 2019.

ZANON, L. B.; PALHARINI, E. M. A química no ensino fundamental de Ciências. Revista Química Nova na Escola, São Paulo, n.2, p. 15-18, nov. 1995. Disponível em: <http://qnesc.sbq.org.br/online/qnesc02/relatos.pdf>. Acesso em: 30 mai. 2019.

\section{Questionário aplicado:}

1. Qual a densidade de uma solução com massa de $8 \mathrm{~g}$ e volume de $2 \mathrm{~cm}^{3}$ ?

2. O que acontece com a densidade de um gás quando o seu volume aumenta? Assinale a alternativa correta:
(A) Aumenta
(B) Diminui
(C) Permanece constante
(D) Não acontece nada
(E) N. D. A.

3. Qual o comportamento das moléculas dos gases? Assinale a alternativa correta:
(A) Espectral
(B) Linear constante
(C) Cúbico de face centrada
(D) Desordenado em várias direções
(E) N. D. A.

4. O que ocorre com um gás quando ele é aquecido em um recipiente fechado? Assinale a alternativa correta:
(A) Ele se dilata, aumentando seu volume
(B) Não acontece nada
(C) Ele perde massa
(D) Ele explode
(E) N. D. A.

5. O que ocorre com o volume de um gás ao aumentar a pressão sobre ele? Marque a alternativa correta:
(A) Aumenta
(B) Diminui
(C) Não acontece nada
(D) Permanece constante
(E) N. D. A. 
Figura 5. História em quadrinhos.

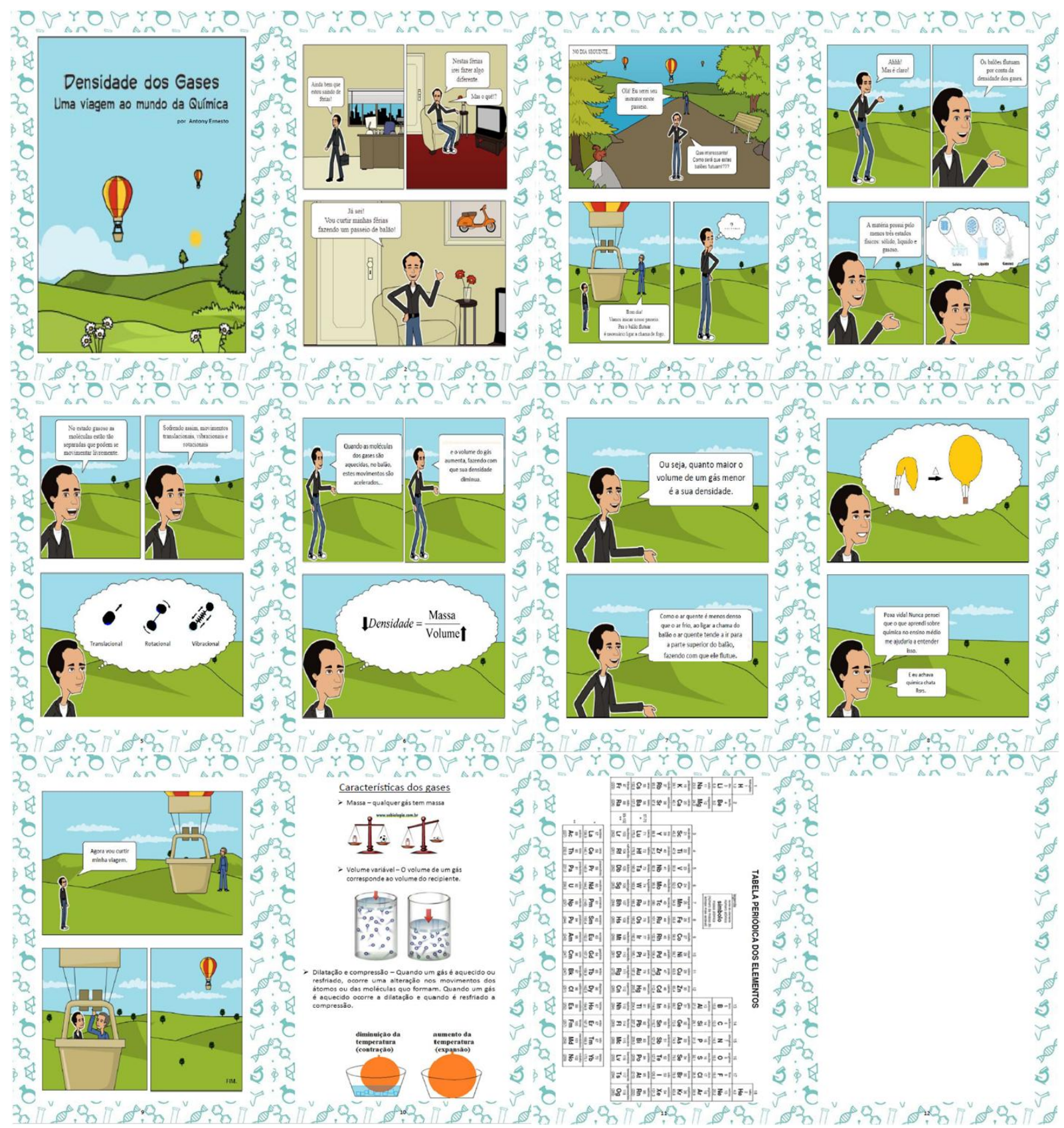

